\title{
Empirical Tests of Exchange Rate Theory
}

\author{
Eric O'N. Fisher \\ California Polytechnic State University
}

\section{Introduction}

There have been very few direct applications of experimental techniques in macroeconomics for two main reasons. First, macroeconomics is about the interaction between markets, and it is not easy to design an elegant treatment that gets at the essence of how a national economy functions. Second, there is a vestigial prejudice that favors econometrics over putatively unorthodox empirical approaches. Still, the Nobel Prize-winning economist Edward Prescott is alleged to have said, "Don't regress; progress!"

This paper takes that methodological exhortation seriously, and it pays homage two recent Nobel Prizes in economics. Following the pioneering work of Vernon Smith and others, I use the laboratory to study some foundations of international finance. Following in the footsteps of Fynn Kydland, Edward Prescott, and others, I eschew esoteric econometric techniques and design direct empirical tests of the three most basic elements of exchange rate theory: purchasing power parity, covered interest parity, and uncovered interest parity.

My research establishes two points. First, each of these three elements of exchange rate theory fares well in the laboratory. Second, not-traded goods and non-stationary domestic prices do cause deviations from simple theoretical predictions, but a non-stationary environment has a more significant effect than does not-traded goods in explaining why simple predictions of exchange rate theories break down.

Perhaps the most celebrated article in the literature on exchange rate econometrics is Meese and Rogoff [9]. Those authors set the standard for a vast literature in empirical international finance. The entire literature on

The author thanks the National Science Foundation for grants SES-9870874 and SES-0111315 that made this work possible. 
experimental economics and exchange rates consist of four papers: Arifovic [1], Noussair, Plott, and Riezman [10], Fisher and Kelly [4], and Fisher [3]. ${ }^{1}$

How does my work contribute to the larger literature on empirical models of exchange rates? My simple treatments may not capture the full complexity of the international monetary system, but experimental economics does complement traditional research using applied econometrics. My results reinforce the notion that both not-traded goods and non-stationary prices contribute to the empirical failure of exchange rate models, but this experiment shows clearly that non-stationary prices have a stronger effect. ${ }^{2}$

\section{Elements of Exchange Rate Theory}

There are three elements that are at the foundation of any theory of international finance. The first is purchasing power parity; nominal exchange rates adjust, at least in the long-run, so that comparable baskets of goods from different countries will cost the same when denominated in a common currency. The second is covered interest parity; most foreign exchange trading among the major money center banks involves simultaneous purchases of spot foreign exchange and resale on the forward market. Since this is a synthetic transaction that entails no risk, it defines the foreign exchange forward premium in terms of home and foreign risk-free rates of interest. The third element is uncovered interest parity. This element states that risk-neutral traders would be willing to hold an open position in foreign exchange if expected dpreciation is less that the difference between home and foreign interest rates. ${ }^{3}$

\section{The Experimental Design}

Table 1 summarizes the experiment's design and also gives goodness-of-fit statistics. Its columns are the three different treatments, and its rows capture different elements of exchange rate theory. Since the experimental design constitutes a two-way layout with five blocks and three treatments, it is easy to examine treatment effects. ${ }^{4}$ A general test has the interpretation that either not-traded goods or non-stationary prices cause different outcomes for at least one of the three elements.

${ }^{1}$ Let me put this number in perspective. A search of EconLit in March 2005 found 19132 hits for the keywords "exchange rates," 1009 hits for "purchasing power parity," and 1182 hits for "money demand."

${ }^{2}$ Using an intuitive statistical decomposition, Engel (1999) showed that not-traded goods prices accounted for almost none of the variability of the U.S. bilateral real exchange rate against several major countries over a long period.

3 The motivated reader can consult Froot and Rogoff [5] or Frankel and Rose [6] for a lengthier discussion of these ideas.

${ }^{4}$ See Hollander and Wolfe [8], chapter 7. 


\begin{tabular}{|c|c|c|c|c|}
\hline \multicolumn{2}{|c|}{} & \multicolumn{3}{|c|}{ Macroeconomic Environment } \\
\cline { 3 - 5 } \multicolumn{2}{|c|}{} & Control & $\begin{array}{c}\text { Not-Traded } \\
\text { Goods }\end{array}$ & $\begin{array}{c}\text { Non-Stationary } \\
\text { Prices }\end{array}$ \\
\hline \multirow{4}{*}{$\begin{array}{c}\text { Element of } \\
\text { Exchange }\end{array}$} & Purchasing & 0.13 & 0.28 & 0.33 \\
Rate Theory & Power Parity & 0.08 & 0.08 & 0.26 \\
\cline { 2 - 5 } & Covered & 0.02 & 0.07 & 0.26 \\
\cline { 2 - 5 } & Interest Parity & & & 0.19 \\
& Uncovered & 0.15 & 0.38 & 0.67 \\
\hline
\end{tabular}

Table 1. Goodness of Fit Statistics, Mean Absolute Percentage Errors

\section{Experimental Procedures}

The sessions were held in between October 2000 and June 2002 at The Ohio State University, and they were conducted by hand, not by computer.

The experimenter auctioned off one unit of currency to each of the four highest bidders; hence foreign exchange was in fixed supply. The experimenter sold domestic goods and foreign goods at fixed prices; hence the markets for commodities exhibited perfectly elastic supply. Domestic currency and foreign currency were not worth anything in and of themselves, but one could buy domestic goods only with domestic currency, and foreign goods only with foreign currency. Thus the experiment imposes two cash-in-advance constraints. In order to buy foreign commodities, a subject had to purchase foreign exchange by bidding in units of domestic currency. The foreign exchange markets were third-price auctions, and thus it is a Nash equilibrium for each subject to bid the common value for a unit of foreign currency.

The foreign exchange market cleared twelve times in the sessions in the first and second blocks of Table 1, and twenty-four times in all the other sessions. The subjects earned about $\$ 25$ on average. The currencies were different kinds of play money. The instructions made the two cash-in-advance constraints very explicit, and they also go into detail about how the call market works. After having read the instructions together with the experimenter aloud, all the subjects answered a series of questions to make sure that they understood the incentives inherent in each design. ${ }^{5}$

\section{Market Equilibrium and Experimental Results}

The no-surplus Nash equilibrium forms the theoretical predictions for the model in every session. There are deviations from the theoretical predictions,

${ }^{5}$ The instructions can be found at http://economics.sbs.ohiostate.edu/efisher/ppp. 


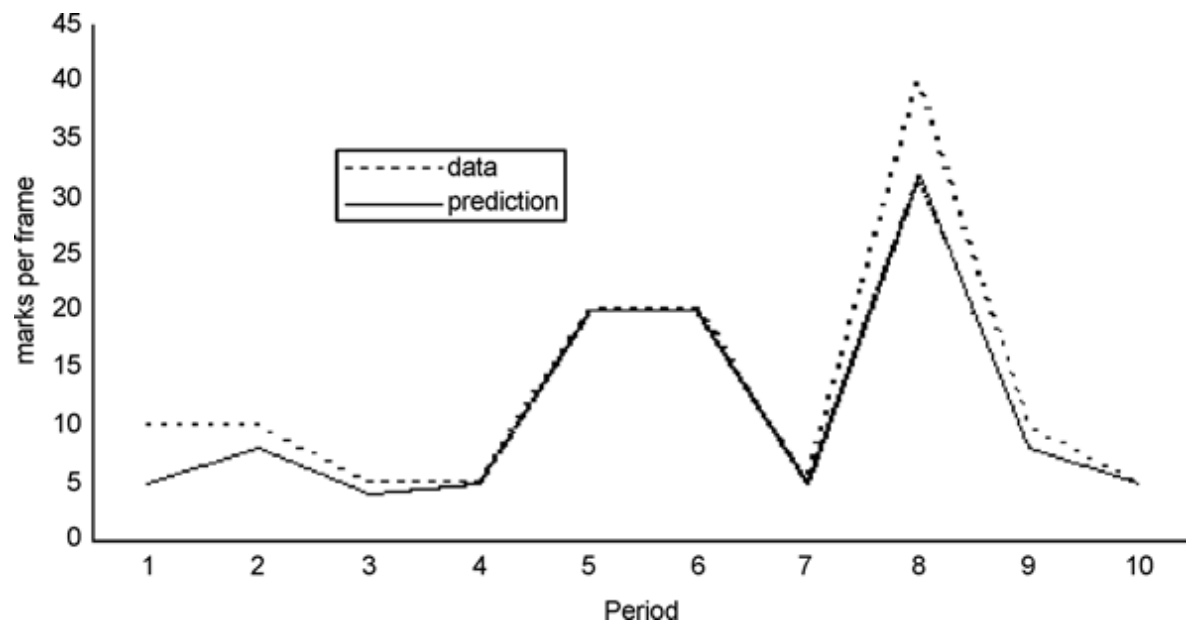

Fig. 1. Purchasing Power Parity, 5 October 00

but the five sessions that constitute the control treatment have remarkably accurate theoretical predictions. The sessions from the treatments with nottraded goods and with non-stationary prices do show greater deviations from the theoretical predictions than those in the control group.

The results are best summarized by graphs. Figures 1 through 3 show the predictions and the actual data for the purchasing power parity five. Figure 1 is the control treatment, Figure 2 is the treatment with not-traded goods, and Figures 3 is the treatment with non-stationary domestic prices.

Three general observations about these fifteen sessions are salient. First, the purchasing power parity, covered interest parity, and uncovered interest parity fare very well. Second, the control sessions exhibit remarkably accurate theoretical predictions. Third, both not-traded goods and non-stationary domestic prices cause deviations from the theoretical predictions, but the biggest deviations from the theoretical predictions seem to occur because of the nonstationary environment.

Table 2 gives the mean absolute percentage errors of the data from the model's predictions. The natural non-parametric test for treatment effects is Friedman's [7] rank sum test. One can reject the null hypothesis of no treatment effect for a test of size 1\%. ${ }^{6}$ The statistics in the third column of Table 2 are much larger than those in the second column. That table presents

${ }^{6}$ In both cases, the Friedman statistic is 8.4, and it has a p-value of .008. There were no ties; the data shown in Table 4 have been rounded for ease of exposition. The exact distribution of this statistic is given in Hollander and Wolfe (1973), Table A.15. It has an asymptotic chi-squared distribution whose degrees of freedom are one less than the number of treatments. 


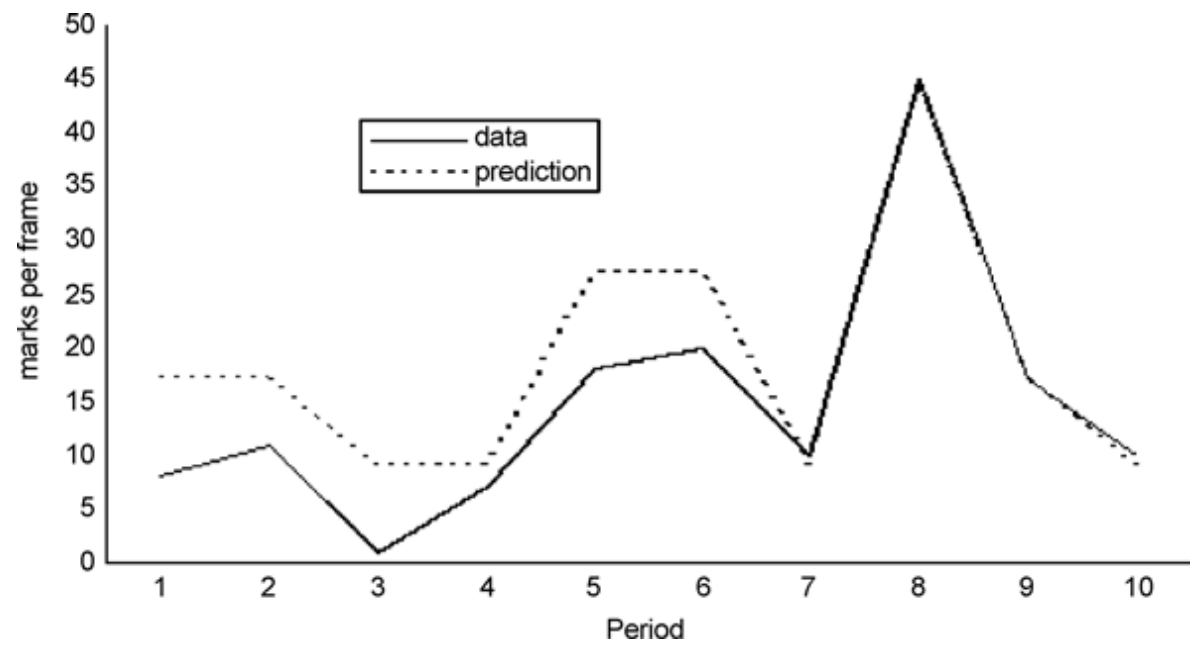

Fig. 2. Not Tradeed Goods Purchasing Power Parity, 8 February 2002

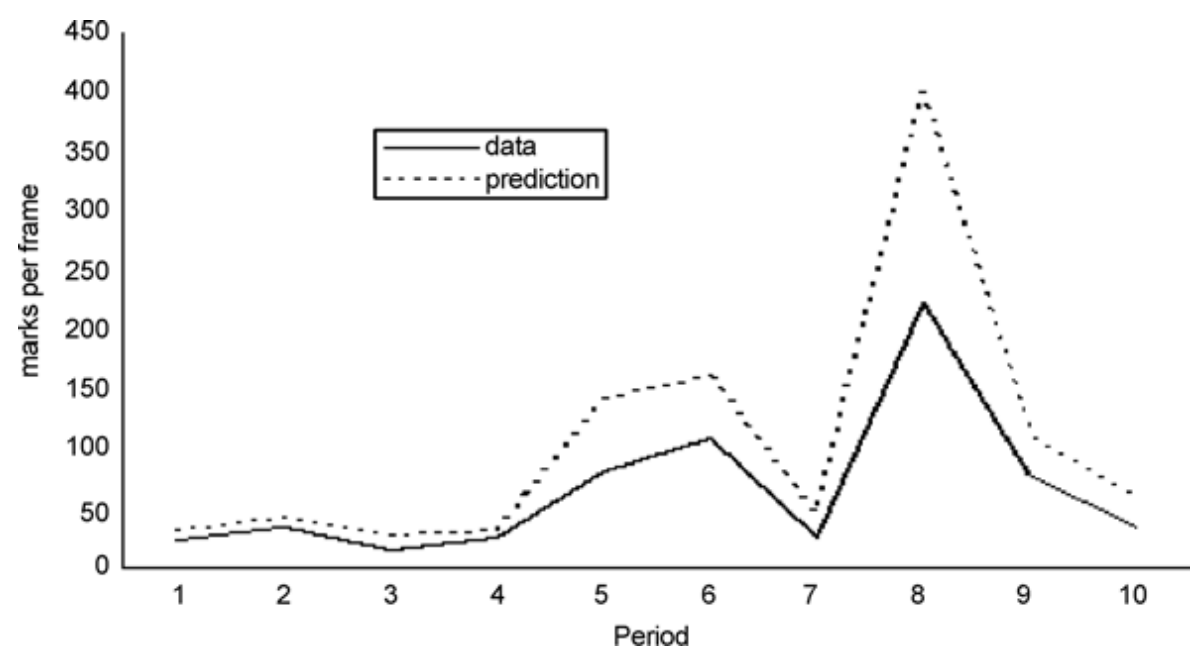

Fig. 3. Not - Stationary Purchasing Power Parity, 1 February 2002 
prima facie evidence that the largest departures from the theory have to do with non-stationary domestic prices.

\section{Conclusion}

The experiment shows that all three elements of exchnage rate theory hold in a simple environment. Exchange rate theory breakd down primarily because of trending prices. The find that not th treatment with traded goods has a much weaker effect than the one with trending prices is the main contributions of this experiment.

I would like to conclude with an exhortation for more experimental research in macroeconomics and international economics. The hallmark of a science is the replication of empirical results. I have shown that the elements of exchange rate theories are vindicated in the laboratory. But I have also used a controlled environment to indicate perhaps that the broad empirical failure of many exchange rate models may have to do with the disparate secular inflation rates that the major industrial have experienced.

\section{References}

1. Arifovic, J (1996) The behavior of the exchange rate in the genetic algorithm and experimental economies, Journal of Political Economy 104: 510-541.

2. Engel C (1999) Accounting for U.S. real exchange rate changes, Journal of Political Economy 107: 507-538.

3. Fisher EO'N (2001) Purchasing power parity and interest parity in the laboratory, Australian Economic Papers 40: 586-602.

4. Fisher EO'N and Kelly FS (2000) Experimental foreign exchange markets," Pacific Economic Review 5: 368-388.

5. Frankel JA, Froot KA (1995) Perspectives on PPP and long-run real exchange rates, Chapter 32 in Handbook of International Economics, Volume 3, (Grossman GM and Rogoff K, eds.), Elsevier, Amsterdam.

6. Frankel JA, Rose AK (1995) Empirical research on nominal exchange rates," Chapter 33 in Handbook of International Economics, Volume 3, (Grossman GM and Rogoff K, eds.), Elsevier, Amsterdam.

7. Friedman M (1937) The use of ranks to avoid the assumption of normality implicit in the analysis of variance, Journal of the American Statistical Association 32: $675-701$.

8. Hollander M, Wolfe DA (1973) Nonparametric statistical methods. John Wiley: New York.

9. Meese RA and Rogoff K (1983) Empirical exchange rate models of the seventies: Do they fit out of sample? Journal of International Economics 14: 3-24.

10. Noussair C, Plott C, Riezman R (1997) The principle of exchange rate determination in an international finance experiment, Journal of Political Economy 105: 822-861. 